\title{
Measuring Contagion between Oil Prices and Stock Markets in the GCC Countries Using a Hybrid Artificial Neural Network Model
}

\author{
M. El Shazly and A. Lou
}

\begin{abstract}
By combining artificial intelligence and genetic training algorithms this paper constructs a hybrid model that measures the degree of contagion between oil prices and stock markets for the Gulf Cooperation Council countries. The model's architecture captures the strength of the pulse that is being transmitted between the oil market and the six markets of the United Arab Emirates, Bahrain, Kuwait, Oman, Qatar and Saudi Arabia over the period 2008-2015. Sensitivity reports suggest that the degree of spillover between oil and global equity markets varies by country and over time. This research seeks to provide insights related to the strength of transmissions and to answer questions that deal with symmetry and diversification. By improving the measurements of the connection strengths that link markets together, more prudent management may be adopted that would enhance the effectiveness of policy implementation.
\end{abstract}

Index Terms-Artificial intelligence, contagion between oil and equity markets, GCC countries.

\section{BACKGROUND}

Though volatility in oil and equity markets is not a new phenomenon, the extreme swings that were experienced following the global financial crisis of 2007-2009 have stretched the economic fabric of most countries especially those of the GCC nations. As a group, the GCC countries share two common characteristics: first, they are closely integrated with the world through oil, and second, their local financial markets are not as mature. To this group of countries, oil is a double edged sword that on the one hand provides them with wealth and economic growth potential yet on the other hand it exposes them to risks generated by the global market that are beyond their control.

The extreme volatility of oil prices between the years 2008-2015 is attributed to market forces on both the supply and demand side. On the supply side, factors that have contributed to the lower oil prices include; the shale revolution, OPEC's decision to leave its market shares unchanged and the expected lifting of Iran's sanctions. On the demand side, the slower global growth in China and emerging markets further suppressed prices pushing them from over \$110 in 2014 to under \$50 per barrel in 2015 [1] .

The risks that the GCC countries face that relate to oil stem from the extreme price swings and their heavy dependence on hydrocarbons [3]. With oil being an integral part of the GCC economies, its volatile prices have

Manuscript received February 26, 2016; revised July 13, 2016.

Mona El Shazly is with the Columbia College, USA (e-mail: melshazly@columbiasc.edu). impacted them in different ways. For most, heavy reliance on oil revenue continues to be the driving force behind the governments' budgetary allocations. For the oil exporting countries, the steep decline in oil prices has had significant impact on their governments' budgets weakening their positions and constraining their spending programs.

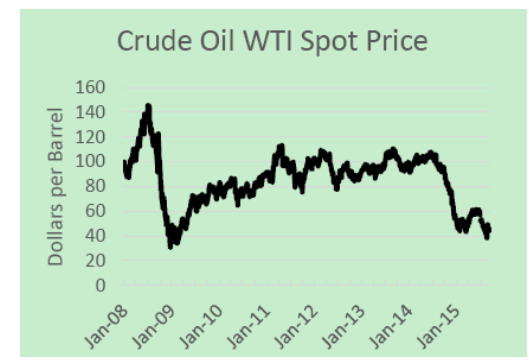

Fig. 1. Crude oil prices [2].

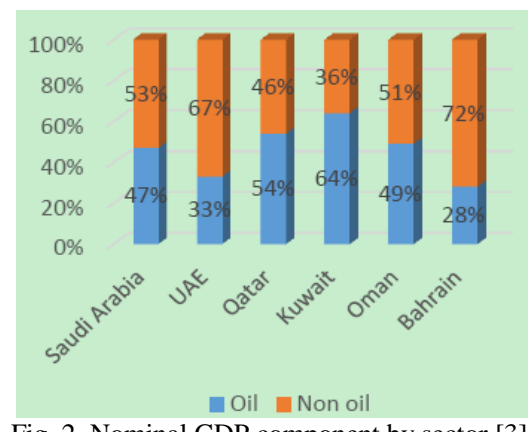

Fig. 2. Nominal GDP component by sector [3]

Though the degree of dependence varies, the collapse of oil prices between 2014-2015 has forced the Gulf countries to borrow and draw on their reserves to meet their domestic expenditures. Fiscal balances were adversely affected turning budget surpluses for 2014 of $\$ 76$ billion (4.5\% of GDP) into projected deficits of $\$ 113$ billion (8\% of GDP) in 2015 [4]. Because these countries have launched ambitious social and economic programs, their budgets have become vulnerable to the lower oil prices. On average, for the GCC countries the fiscal break-even price of oil for 2015 is \$86/barrel.

The slump in oil prices has also resulted in major setbacks on the Gulf countries' efforts in establishing a financial hub in the region. Equity markets have been plagued by internal factors that have constrained their maturity and external shocks that have increased their vulnerability. Internal fragility is attributed to [6]:

1) Smallness of size

2) Low levels of liquidity

3) Listings are concentrated in a few sectors

4) Governments and families exercise significant control 
5) Limited access for foreign investors

These constraints limited the GCC markets' ability to absorb the adverse spill-over transmitted by the global financial crisis of 2008 and increased their exposure to the external shocks.

TABLE I: FISCAL BREAK-EVEN PRICES OF OIL [5]

\begin{tabular}{lcc}
\multicolumn{2}{c}{ TABLE I: FISCAL BREAK-EVEN PRICES OF OIL [5] } \\
\hline \hline Country & $\begin{array}{c}\mathbf{2 0 1 4} \\
\text { \$/Barrel }\end{array}$ & $\mathbf{2 0 1 5} \mathbf{\text { \$/Barrel }}$ \\
\hline Bahrain & 126 & 130 \\
\hline Oman & 103 & 102 \\
\hline Saudi Arabia & 98 & 103 \\
\hline UAE & 73 & 75 \\
\hline Qatar & 59 & 65 \\
\hline Kuwait & 51 & 54 \\
\hline GCC & 83 & 86 \\
\hline \hline
\end{tabular}

This research seeks to determine the strength of contagion between oil and equity markets by answering the following questions:

1) Have connection strengths between oil prices and stock markets increased over time?

2) Has diversification within the GCC countries reduced the risk of oil price volatility?

3) Is contagion stronger during periods of crisis?

4) Is the pulse transmitted from the oil market and the stock markets symmetric?

The paper is divided into four sections. In Section II the methodology is discussed and the model's architecture is described. The results are presented and analyzed in Section III followed by a concluding section that offers insights and remarks that may guide policy by providing a venue for discussion based on the research results.

\section{Methodology AND Model ARChitecture}

The hybrid model used in this paper combines artificial neural networks ANNs with a genetic training optimizer (GTO). The basic network architecture applied is that of a multi-layer perceptron model using the Brainmaker Software program. Amongst the advantages of this architectural design is that it is model free, the estimators are non-parametric and are capable of processing imperfect data, generalizing, and dealing with complex relationships.

The network's ability of learning relies on backpropagation which uses delayed feedback and as such the solutions evolve from within following a training process. In search of the optimal network design, a three stepped process is followed. First, a set of neural network models are developed, trained, tested and rated. Second, those networks that are rated as being good or fit are saved or survive, and are then allowed to reproduce. Third, the best-rated networks generated are saved and fed back to the neural network model. The connection weights of the optimal network are then tested and evaluated [7].

Genetic algorithms are based on evolutionary processes, and on Darwin's concept of natural selection. Unlike traditional statistical techniques, genetic algorithms (GAs) seek to identify optimal solutions by searching entire populations of candid solutions in parallel. The advantage to this approach is that it is more likely to estimate the true global optimum, and much less likely to get stuck at a local optimum. Another appealing feature of GAs is that their performance is largely unaffected by initial conditions. Furthermore, they are capable of finding relationships between inputs and outputs even when the patterns are ill defined [8].

Using weekly data for the $2008-2015$ four subset periods are identified: 2008-09, 2008-2010, 2011-13 and 2014-15. Raw data was obtained from MarketsToday.net [9].

The network architecture for all test periods is built using three layers: input, hidden and output layer. The data fed into the network is divided into a training and testing set. During training, weights are assigned randomly between nodes that connect the input layer with the hidden and output layer. The guesses that are generated are compared with the actual value and an error is calculated which is then used to readjust the weights. The process is periodically interrupted and tested until the desired pre-specified level is reached. During training and testing the tolerance level was set at 0.10 , the transfer function between input and hidden, and hidden and output layers is the sigmoid transfer function.

To measure the degree of contagion between the six GCC equity markets with the oil market, the S\&P Global 1200 and the S\&P 500 Index, we analyze the sensitivity reports generated by GTO of the optimal network [10].

\section{EMPIRICAL RESULTS}

Each of the six networks: Tadawul All Share Index for the Saudi Stock Exchange, Qatar Exchange Index, Abu Dhabi Securities Exchange for the UAE, MSM 30 for Oman, Bahrain All Share Index, and Kuwait Stock Exchange Index, were each run separately. The network parameters are twelve nodes for the input layer representing the 1,2, 3 and 4 lagged $\log$ values for the oil, S\&P 500 and S\&P Global 1200 average weekly values. The hidden layer has twelve nodes and the output layer one node for the equity index.

Training and a testing were set at 0.10 tolerance level with a learning rate of 1.00 . The results reported are for the optimal GTO network generated by the hybrid model. Sensitivity measures are used as a proxy for the degree of contagion between the inputs and outputs. Appendix A shows the absolute mean sensitivity values for all inputs for each of the sub period.

The absolute mean sensitivity of the inputs reflects the average change of the output neuron over all the facts when each of the inputs is varied by $+/-10 \%$. Appendix B extracts the three inputs with the highest degree of sensitivity for each of the GCC markets. The reports generated are used to answer the questions raised by this study.

Between 2008 and 20015, oil prices suffered two sharp declines one in 2008-09 and the other in 2014-2015. While the first was more pronounced, equity markets of the GCC countries showed greater sensitivity towards transmissions induced by the global recession through S\&P 500 and S\&P Global 1200 than they did to oil. The 2014-15 oil plunge however had a greater and more widespread effect on the GCC markets. This finding confirms that connection strengths between oil prices and equity markets of the GCC countries increased over time.

The results reported in Appendix B confirm that countries that are more diversified like Bahrain, Oman and the UAE 
are less sensitive to oil price movements compared to Saudi Arabia and Kuwait that have a higher degree of dependence. Our findings for the two periods 2008-10 and 2011-13 confirm this conclusion. However when oil prices dropped sharply in 2014-15, contagion was more widespread affecting all GCC markets regardless of their degree of diversification. This leads us to conclude that diversification offers equity markets protection but not insulation from oil price volatility.

The sensitivity results moreover assert that during periods of crisis, contagion is stronger. In 2014-15 the precipitous decline in oil prices increased the sensitivity coefficient for all the oil input variables. Likewise in 2011-13 when global equity markets recorded strong gains and rebounded from the global recession, they too transmitted a stronger pulse that affected the GCC markets.

As for the question on symmetry of transmission between oil prices and stock markets, we find our results to be inconclusive. Although the findings show that both oil and stock markets affect the GCC equity markets, we are unable to ascertain that their effect is symmetric.

\section{CONCLUDING REMARKS}

Despite the efforts made by the GCC economies to reduce their dependence on oil, their exposure to extreme price volatility has offered them limited protection. For those countries like Saudi Arabia and Kuwait with heavy reliance on hydrocarbon revenues to finance their spending, their governments have seen their budget surpluses erode with the collapse in oil prices. By expending resources to finance social programs such as education, health care, housing and infrastructure and without having alternate sources of financing or income taxation, their ability to sustain these programs may be jeopardized.

To sustain the economic growth that the GCC countries have achieved, it is necessary for them to revise their budgetary allocations as well as their revenue sources. One important issue that needs to be addressed on the expenditure side is employment. The public sector absorbs a big cost of employment in the form of wages and salaries. While nationals account for $90 \%$ of total employment in the public sector, the private sector predominately relies on expatriates [11].

The most recent slump in oil prices should provide an impetus for the GCC countries to accelerate their efforts towards structural reforms. Focusing on diversification and reducing their reliance on oil should become a primary objective. Plans to manage their economies and sustain their growth should be implemented with a sense of preparedness to expand their tax base and reduce the benefits and subsidies the governments pays out.

As they shape their future foreign policies, the GCC countries must forge ties with the world that are founded on a broader set of interests and goals. The challenges the GCC countries face today do not just stem from uncertainty resulting from oil markets but also include issues that deal with social, economic and political factors.

Managing a growing youth population and local employment impose huge domestic challenges. Other social elements like housing, health care and education that absorb most of the budget allocations have to be considered with careful deliberation. Economic pressures arising from inflation, slow growth and investments have to be alleviated. All these elements hinge on ensuring political stability in a regional environment that is anything but stable.

APPENDIX A: SENSITIVITY RESULTS

\begin{tabular}{|l|r|r|r|r|r|r|}
\hline 2008:09-2009:03 & \multicolumn{1}{|l|}{ Saudi Arabia } & \multicolumn{1}{l|}{ UAE } & \multicolumn{1}{l|}{ Qatar } & \multicolumn{1}{l|}{ Kuwait } & \multicolumn{1}{l|}{ Oman } & \multicolumn{1}{l|}{ Bahrain } \\
\hline S\&P_1 & 0.0991 & 0.1546 & 0.2051 & 0.1051 & 0.2215 & 0.1522 \\
\hline S\&P_2 & 0.0821 & 0.0966 & 0.0562 & 0.1113 & 0.0281 & 0.0255 \\
\hline S\&P_3 & 0.0839 & 0.0575 & 0.0795 & 0.0572 & 0.0484 & 0.0619 \\
\hline S\&P_4 & 0.0742 & 0.1947 & 0.0584 & 0.0414 & 0.0825 & 0.0501 \\
\hline SPG_1 & 0.0322 & 0.1399 & 0.0735 & 0.1125 & 0.1260 & 0.1334 \\
\hline SPG_2 & 0.0209 & 0.0799 & 0.0814 & 0.0560 & 0.0439 & 0.0845 \\
\hline SPG_3 & 0.0508 & 0.1372 & 0.1640 & 0.0393 & 0.0715 & 0.1180 \\
\hline SPG_4 & 0.0684 & 0.0574 & 0.0834 & 0.0368 & 0.0308 & 0.0483 \\
\hline Oil_1 & 0.0500 & 0.1232 & 0.1094 & 0.0896 & 0.0341 & 0.1073 \\
\hline Oil_2 & 0.0523 & 0.0707 & 0.0841 & 0.0397 & 0.0403 & 0.0801 \\
\hline Oil_3 & 0.1186 & 0.0529 & 0.1115 & 0.0798 & 0.0473 & 0.0671 \\
\hline Oil_4 & 0.0422 & 0.0645 & 0.0848 & 0.0754 & 0.0579 & 0.0491 \\
\hline r-squared & 0.9283 & 0.9697 & 0.9682 & 0.9351 & 0.9345 & 0.9711 \\
\hline
\end{tabular}

\begin{tabular}{|l|r|r|r|r|r|r|}
\hline 2008:01 - 2010:12 & Saudi Arabia & \multicolumn{1}{l|}{ UAE } & Qatar & \multicolumn{1}{l|}{ Kuwait } & Oman & Bahrain \\
\hline S\&P_1 & 0.0487 & 0.0591 & 0.0565 & 0.0233 & 0.0579 & 0.1361 \\
\hline S\&P_2 & 0.0188 & 0.1009 & 0.0170 & 0.0281 & 0.0155 & 0.0426 \\
\hline S\&P_3 & 0.0195 & 0.0960 & 0.0599 & 0.0315 & 0.0231 & 0.0896 \\
\hline S\&P_4 & 0.0213 & 0.0757 & 0.0203 & 0.0362 & 0.0674 & 0.0677 \\
\hline SPG_1 & 0.0304 & 0.0517 & 0.0372 & 0.0356 & 0.0256 & 0.0809 \\
\hline SPG_2 & 0.0337 & 0.0641 & 0.0339 & 0.0430 & 0.0317 & 0.1104 \\
\hline SPG_3 & 0.0595 & 0.0822 & 0.0585 & 0.0260 & 0.0436 & 0.1158 \\
\hline SPG_4 & 0.0362 & 0.0728 & 0.0458 & 0.0250 & 0.0266 & 0.0224 \\
\hline Oil_1 & 0.0483 & 0.0683 & 0.0358 & 0.0757 & 0.0168 & 0.0662 \\
\hline Oil_2 & 0.0458 & 0.0781 & 0.0311 & 0.0270 & 0.0335 & 0.0584 \\
\hline Oil_3 & 0.0274 & 0.0632 & 0.0341 & 0.0375 & 0.0443 & 0.0556 \\
\hline Oil_4 & 0.0294 & 0.0575 & 0.0336 & 0.0390 & 0.0330 & 0.0561 \\
\hline r-squared & 0.9109 & 0.8931 & 0.8987 & 0.8930 & 0.8748 & 0.8575 \\
\hline
\end{tabular}

\begin{tabular}{|l|r|r|r|r|r|r|}
\hline 2011:01 - 2013:12 & Saudi Arabia & \multicolumn{1}{l|}{ UAE } & \multicolumn{1}{l|}{ Qatar } & \multicolumn{1}{l|}{ Kuwait } & Oman & Bahrain \\
\hline S\&P_1 & 0.0268 & 0.0672 & 0.0444 & 0.0397 & 0.0460 & 0.0609 \\
\hline S\&P_2 & 0.0162 & 0.0749 & 0.0418 & 0.0352 & 0.0358 & 0.0378 \\
\hline
\end{tabular}




\begin{tabular}{|c|c|c|c|c|c|c|}
\hline S\&P_3 & 0.0146 & 0.0573 & 0.0530 & 0.0197 & 0.0413 & 0.0554 \\
\hline S\&P_4 & 0.0190 & 0.0434 & 0.0308 & 0.0368 & 0.0373 & 0.0502 \\
\hline SPG_1 & 0.0175 & 0.0357 & 0.0793 & 0.0195 & 0.0541 & 0.0275 \\
\hline SPG_2 & 0.0253 & 0.0451 & 0.0614 & 0.0322 & 0.0474 & 0.0333 \\
\hline SPG_3 & 0.0219 & 0.0756 & 0.0512 & 0.0256 & 0.0292 & 0.0486 \\
\hline SPG_4 & 0.0411 & 0.0634 & 0.0354 & 0.0372 & 0.0683 & 0.0570 \\
\hline Oil_1 & 0.0399 & 0.0428 & 0.0453 & 0.0289 & 0.0280 & 0.0364 \\
\hline Oil_2 & 0.0403 & 0.0464 & 0.0812 & 0.0289 & 0.0315 & 0.0142 \\
\hline Oil_3 & 0.0290 & 0.0475 & 0.0454 & 0.0180 & 0.0101 & 0.0544 \\
\hline Oil_4 & 0.0731 & 0.0619 & 0.0635 & 0.0388 & 0.0366 & 0.0266 \\
\hline r-squared & 0.9052 & 0.8654 & 0.8877 & 0.8724 & 0.8941 & 0.9120 \\
\hline 2014:01 - 2015:09 & Saudi Arabia & UAE & Qatar & Kuwait & Oman & Bahrain \\
\hline S\&P_1 & 0.0371 & 0.0564 & 0.0255 & 0.0306 & 0.0338 & 0.0651 \\
\hline S\&P_2 & 0.0474 & 0.0298 & 0.0802 & 0.0509 & 0.0249 & 0.0136 \\
\hline S\&P_3 & 0.0315 & 0.0736 & 0.0259 & 0.0503 & 0.0693 & 0.0833 \\
\hline S\&P_4 & 0.0564 & 0.0530 & 0.0304 & 0.0416 & 0.0394 & 0.0598 \\
\hline SPG_1 & 0.0308 & 0.0413 & 0.0223 & 0.0485 & 0.0373 & 0.0379 \\
\hline SPG_2 & 0.0695 & 0.1648 & 0.0491 & 0.0289 & 0.0805 & 0.0521 \\
\hline SPG_3 & 0.0550 & 0.0684 & 0.0457 & 0.0512 & 0.0342 & 0.0422 \\
\hline SPG_4 & 0.0580 & 0.0657 & 0.0431 & 0.0391 & 0.0419 & 0.0393 \\
\hline Oil_1 & 0.0793 & 0.0785 & 0.0527 & 0.0671 & 0.0760 & 0.0345 \\
\hline Oil_2 & 0.0690 & 0.0942 & 0.0673 & 0.0834 & 0.0631 & 0.0690 \\
\hline Oil_3 & 0.0828 & 0.0488 & 0.0426 & 0.0444 & 0.0210 & 0.0420 \\
\hline Oil_4 & 0.0756 & 0.0454 & 0.0639 & 0.0353 & 0.0292 & 0.0269 \\
\hline r-squared & 0.9359 & 0.9402 & 0.8224 & 0.9041 & 0.9415 & 0.8641 \\
\hline
\end{tabular}

\begin{tabular}{|c|c|c|c|c|c|c|c|c|c|c|c|c|}
\hline Test Periods & \multicolumn{2}{|c|}{ Saudi Arabia } & \multicolumn{2}{|c|}{ UAE } & \multicolumn{2}{|c|}{ Qatar } & \multicolumn{2}{|c|}{ Kuwait } & \multicolumn{2}{|c|}{ Oman } & \multicolumn{2}{|c|}{ Bahrain } \\
\hline \multirow{3}{*}{$\begin{array}{l}\text { 2008:09 - } \\
\text { 2009:03 }\end{array}$} & Oil_3 & 0.1186 & S\&P_4 & 0.1947 & S\&P_1 & 0.2051 & SPG_1 & 0.1125 & S\&P_1 & 0.2215 & S\&P_1 & 0.1522 \\
\hline & S\&P_1 & 0.0991 & S\&P_1 & 0.1546 & SPG_3 & 0.1640 & S\&P_2 & 0.1113 & SPG_1 & 0.1260 & SPG_1 & 0.1334 \\
\hline & S\&P_3 & 0.0839 & SPG_1 & 0.1399 & Oil_3 & 0.1115 & S\&P_1 & 0.1051 & S\&P_4 & 0.0825 & SPG_3 & 0.1180 \\
\hline \multirow{3}{*}{$\begin{array}{l}2008: 01- \\
\text { 2010:12 }\end{array}$} & SPG_3 & 0.0595 & S\&P_2 & 0.1009 & S\&P_3 & 0.0599 & Oil_1 & 0.0757 & S\&P_4 & 0.0674 & S\&P 1 & 0.1361 \\
\hline & S\&P_1 & 0.0487 & S\&P_3 & 0.0960 & SPG_3 & 0.0585 & SPG_2 & 0.0430 & S\&P_1 & 0.0579 & SPG_3 & 0.1158 \\
\hline & Oil_1 & 0.0483 & SPG_3 & 0.0822 & $S \& P \_1$ & 0.0565 & Oil_4 & 0.0390 & Oil_3 & 0.0443 & SPG_2 & 0.1104 \\
\hline \multirow{3}{*}{$\begin{array}{l}\text { 2011:01 - } \\
\text { 2013:12 }\end{array}$} & Oil_4 & 0.0731 & SPG_3 & 0.0756 & Oil_2 & 0.0812 & S\&P_1 & 0.0397 & SPG_4 & 0.0683 & S\&P_1 & 0.0609 \\
\hline & SPG_4 & 0.0411 & S\&P_2 & 0.0749 & SPG_1 & 0.0793 & Oil_4 & 0.0388 & SPG_1 & 0.0541 & SPG_4 & 0.0570 \\
\hline & $\begin{array}{l}\text { Oil_2 } \\
\end{array}$ & 0.0403 & S\&P_1 & 0.0672 & Oil_4 & 0.0635 & SPG_4 & 0.0372 & SPG_2 & 0.0474 & S\&P_3 & 0.0554 \\
\hline \multirow{3}{*}{$\begin{array}{l}\text { 2014:01 - } \\
\text { 2015:09 }\end{array}$} & Oil_3 & 0.0828 & SPG_2 & 0.1648 & S\&P_2 & 0.0802 & Oil_2 & 0.0834 & SPG_2 & 0.0805 & S\&P_3 & 0.0833 \\
\hline & Oil_1 & 0.0793 & Oil_2 & 0.0942 & Oil_2 & 0.0673 & Oil_1 & 0.0671 & Oil_1 & 0.0760 & Oil_2 & 0.0690 \\
\hline & Oil_4 & 0.0756 & Oil_1 & 0.0785 & Oil_4 & 0.0639 & SPG_3 & 0.0512 & S\&P_3 & 0.0693 & S\&P_1 & 0.0651 \\
\hline
\end{tabular}

*Three most significant inputs

\section{REFERENCES}

[1] International Monetary Fund, "World economic and financial survey, regional economic outlook, Middle East and Central Asia," Washington, D.C., October 15, 2015.

[2] U.S. Energy Information Administration. (2008-2015). [Online]. Available: http://www.eia.gov/petroleum/

[3] A. Capital, "GCC budget analysis," Jeddah, Kingdom of Saudi Arabia August 2014

[4] IMF Regional Economic Outlook Update, May 2015.

[5] Petro diplomacy: The political economy of volatile oil prices, Conference Report \#1, International Institute of Finance: The Arab Gulf States Institute in Washington, 2015.

[6] S. Kern, "Current issues: Global financial markets - long-term prospects for finance in the Gulf Region," Deutcsche Bank Research, Frankfurt am Main, Germany, 2012.

[7] M. R. El Shazly and H. E. El Shazly, "Forecasting currency prices using a genetically evolved neural network architecture," International Review of Financial Analysis, vol. 8, no. 1, pp. 67-82, 1999.

[8] J. Kingdon, Intelligent Systems and Financial Forecasting, Berlin: Springer-Verlag, 1997.

[9] WideVision. [Online]. AZCO, Available: http://www.marketstoday.net/markets/All-Markets/0/en/

[10] C. S. Software, Brain Maker-Neural Network Simulation Software User's Guide and Reference Manual, Nevada City, CA, 1993.

[11] M. Tadros, "The GCC economies: Weathering the oil slump?" The Arab Gulf States Institute in Washington, Washington DC, 2015.

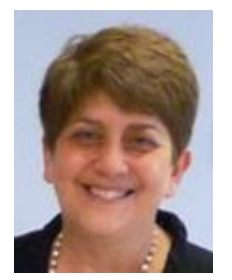

Mona El Shazly was born in Alexandria, Egypt, she received both a B.A. and an M.A. in economics from the American University in Cairo in Egypt in 1977, 1982 and a Ph.D. in international economics from the University of South Carolina in Columbia, SC, USA in 1987.

She has over twenty five years of teaching experience at Columbia College in SC where she is Professor of Economics and International Business. Her teaching experience includes appointments in London, England, Lethbridge, Canada and Cairo, Egypt. She has served as the director of the Center of Economic Education at Columbia College and a consultant on currency convertibility and foreign investments to Russia, Estonia and Belarussia.

Dr. El Shazly's research interests and publications are in the area of international finance focusing on forecasting and market analysis. Her recent publications have focused on the Arab Gulf region and on constructing financial models using artificial neural networks.

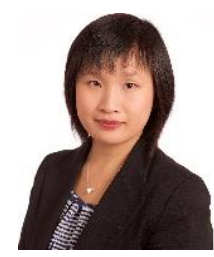

Alice Lou was born and raised in Macao, China. She received a B.S. in mathematics from Columbia College, Columbia, SC, USA in 2007 and a M.S. in operations research from Columbia University, in New York, NY, USA in 2008.

Ms. Lou joined the Faculty of Columbia College immediately after her graduate studies in 2008 as a lecturer of Mathematics. Her research interests include mathematical finance, international capital markets, and operational management. 